\title{
Changes of Ethyl Carbamate in Yellow Rice Wine during Shelf-Life and Formation in Simulated Ethanol and Urea Solutions
}

\author{
Pinggu Wu ${ }^{1, *}$, Chenggang Cai ${ }^{2}$, Dajin Yang ${ }^{3}$, Liyuan Wang ${ }^{1}$, Yan Zhou ${ }^{1}$, Xianghong Shen ${ }^{1}$, Bingjie Ma ${ }^{1}$, Jun Tan ${ }^{1}$ \\ ${ }^{1}$ Zhejiang Provincial Center for Disease Control and Prevention, No. 630 Xincheng Road, Hangzhou, China \\ ${ }^{2}$ School of Biological and Chemical Engineering, Zhejiang University of Science and Technology, 328 Liuhe Road, Hangzhou, China \\ ${ }^{3}$ The National Center for Food Safety Risk Assessment, Beijing, China \\ *Corresponding author:pgwu@cdc.zj.cn
}

Received June 03, 2014; Revised November 03, 2014; Accepted November 05, 2014

\begin{abstract}
Changes of Ethyl carbamate (EC) in yellow rice wine during shelf life and Formation of EC in simulated ethanol and urea mixed solutions were analyzed. The results showed that EC presented in bottled yellow rice wine was more than that of bagged during storage. EC decreased in the first 200 days, then kept an upward tendency and reached 421 and $378 \mu \mathrm{g} / \mathrm{kg}$ till 600 days in bottled and bagged wines, respectively. High concentrations of urea and ethanol accelerated EC formation. EC increased to $591 \mu \mathrm{g} / \mathrm{kg}$ in solutions of $40 \mathrm{mg} / \mathrm{kg}$ urea and $40 \%$ ethanol, while for $20 \%$ ethanol, EC reached $189 \mu \mathrm{g} / \mathrm{kg}$. After 61 days reaction of 35, $20 \mathrm{and} 5 \mu \mathrm{g} / \mathrm{mL}$ urea with 30\% and 15\% ethanol, EC formed 283.1, 171 and 42.8 as well as 144, 99.1 and $23 \mu \mathrm{g} / \mathrm{mL}$, respectively. The results directly validated EC formation caused by urea and ethanol, which was also the main reason for EC increasing in yellow rice wine during shelf life.
\end{abstract}

Keywords: Ethyl carbamate, yellow rice wine, food safety

Cite This Article: Pinggu Wu, Chenggang Cai, Dajin Yang, Liyuan Wang, Yan Zhou, Xianghong Shen, Bingjie Ma, and Jun Tan, "Changes of Ethyl Carbamate in Yellow Rice Wine during Shelf-Life and Formation in Simulated Ethanol and Urea Solutions.” Journal of Food and Nutrition Research, vol. 2, no. 12 (2014): $872-875$. doi: 10.12691/jfnr-2-12-2.

\section{Introduction}

Ethyl carbamate (EC) is genotoxic and carcinogenic in animal species [1,2], it was re-classified as a group 2A carcinogen by the World Health Organization's International Agency for Research on Cancer [3]. EC was widely present in the fermented foods such as alcohol beverages, soy sauce and etc, the contents in several alcohol beverages had been analyzed during production [4-17] including the yellow rice wine. The yellow rice wine is a traditional fermented alcohol drink in china and largely consumed every year. The typical production process of the yellow rice wine includes rice soaking, steaming, addition of starter culture, pre-fermentation, post-fermentation, squeezing, addition of caramel color, frying, package and storage. EC was widely presented in alcohol wines including the yellow rice wine $[8,12,13,14,18,19,20]$, several studies showed that EC was mainly produced by reaction between urea and ethanol in the alcohol beverages $[8,21,22,23]$ during the yellow rice wine production.

Usually the yellow rice wines in China were bottled and bagged stored in the supermarkets. The aroma and flavor components including EC in the rice wines increased with the rise of the storage time. Till now, little studies have been concerned on the change of EC in the yellow rice wines during their shelf life in different packages and there were scarcely studies on the process of EC production between urea and ethanol. To understand the change of EC during storage of the yellow rice wines and to illustrate EC formation influenced by ethanol and urea, two types packed yellow rice wines and the mixtures of several quantities of urea and ethanol were stored and measured periodically.

\section{Materials and Methods}

\subsection{Samples}

The yellow rice wine samples of over 5 years in bottled and bagged packages were bought from a local supermarket, both the two kind of wines contained 20 small individual packages. The wines were stored at room temperature in our lab for over 600 days and were used for periodical analysis.

\subsection{EC Analysis}

EC determination was carried out as the AOAC [24] first action method with minor modifications [13]. Briefly, the $\mathrm{d}_{5}$-ethyl carbamate was used as an internal standard. A $2.0 \mathrm{~g}$ wine sample containing $100 \mu \mathrm{L} 1.0 \mu \mathrm{g} / \mathrm{mL} \mathrm{d}_{5}$-ethyl 
carbamate was added into a centrifuge tube and vortexed for $1 \mathrm{~min}$. A diatomite solid-phase extraction column was used and the analyte was eluted from the mixture with 10 $\mathrm{mL}$ of $5 \%$ ethyl acetate after $10 \mathrm{~min}$ of short static stretches. The resulting eluate was collected, dried by anhydrous sodium sulfate and concentrated using $\mathrm{N}_{2}$ flow at $30^{\circ} \mathrm{C}$. The analyte was further diluted with methanol to a final volume of $1 \mathrm{~mL}$ for GC/MS analysis. All samples were measured three times and the data were presented as the average of the three measured values.

\subsection{EC Formation in Ethanol and Urea Solutions}

Urea in $40 \mathrm{mg} / \mathrm{kg}$ (the general urea concentration in the yellow rice wines) was added to $20 \%$ and $40 \%$ ethanol water solutions, the mixed solutions were stored at $37^{\circ} \mathrm{C}$ and EC was analyzed intervals, then 5, 20, $35 \mu \mathrm{g} / \mathrm{L}$ urea were added to $15 \%$ (the general alcohol content in yellow rice wines) and $30 \%$ ethanol water solution, the mixed solutions were stored at $37^{\circ} \mathrm{C}$ and EC was measured periodically.

\section{Results and Discussion}

\subsection{EC Changes during Shelf Life}

The bottled and bagged rice wines were stored at room temperature for over 600 days. The results in Figure 1 showed that EC concentration in the bottle and bag packed rice wines decreased during the beginning to 250 days, EC decreased from $210 \mu \mathrm{g} / \mathrm{kg}$ to $184 \mu \mathrm{g} / \mathrm{kg}$ in the bottled wines, while the bagged wines were from $196 \mu \mathrm{g} / \mathrm{kg}$ to $158 \mu \mathrm{g} / \mathrm{kg}$, then EC in bottled and bagged wines reached 421 and $378 \mu \mathrm{g} / \mathrm{kg}$ till 600 days, respectively.

Some studies had surveyed EC contents in the yellow rice wines [8,12,13,14,18,19,20], but little had been concerned about EC changes during shelf life. The results in this study showed that EC had a total rise tendency during its shelf life with a little drop in the first 250 days. Similar result was reported in the red wine stored from 1997 to 2001, EC in the newly produced red wines decreased firstly, then increased in the next two years during storage [25].

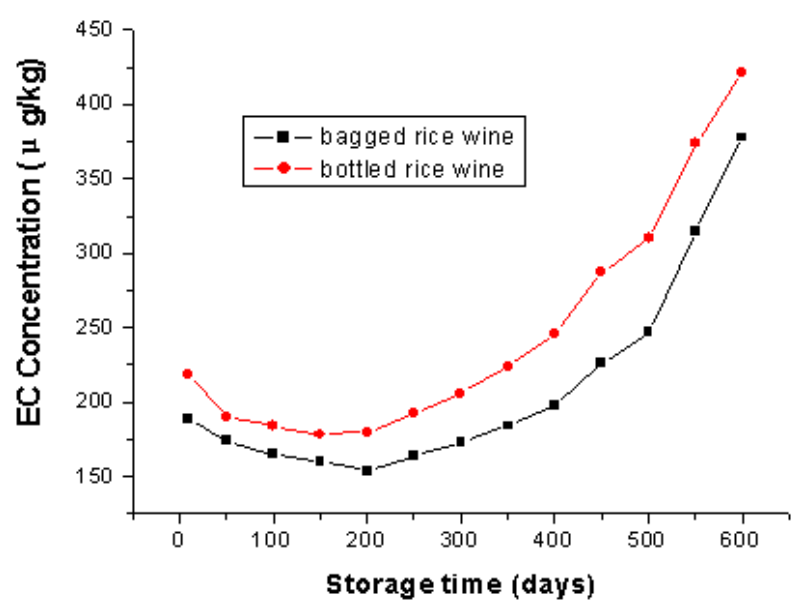

Figure 1. EC changes in yellow rice wine during shelf life

\subsection{EC formation in the Simulated Solutions}

\subsubsection{Effects of Ethanol on EC Formation}

Urea was added to $20 \%$ and $40 \%$ ethanol water solutions to $40 \mathrm{mg} / \mathrm{kg}$ (the generally urea concentration in the yellow rice wines), then the mixed solutions were stored at $37^{\circ} \mathrm{C}$ and EC was analyzed intervals. EC formation and changes in the mixture solutions were shown in Figure 2.

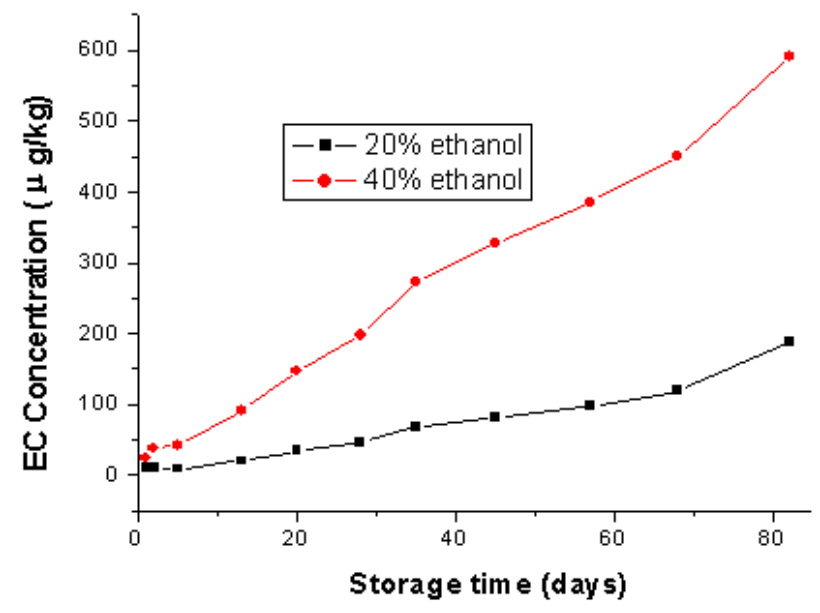

Figure 2. EC formation in ethanol and $40 \mu \mathrm{g} / \mathrm{mL}$ urea solutions at $37{ }^{\circ} \mathrm{C}$

The results indicated that EC formed continuously from the beginning, after 82 days, EC reached $189 \mu \mathrm{g} / \mathrm{kg}$ and $591 \mu \mathrm{g} / \mathrm{kg}$ in $20 \%$ and $40 \%$ ethanol, respectively, which showed that EC was formed by the reaction of ethanol and urea, and $40 \%$ ethanol produced more EC than that of $20 \%$ ethanol.

\subsubsection{Effects of Urea on EC formation}

Different quantities of urea were added to $15 \%$ (the generally alcohol content in yellow rice wines) and 30\% ethanol solution to the level of 5, 20 and $35 \mu \mathrm{g} / \mathrm{mL}$, then the mixed solutions were stored at $37^{\circ} \mathrm{C}$ and EC was analyzed intervals. The results were indicated in Figure 3 and Figure 4.

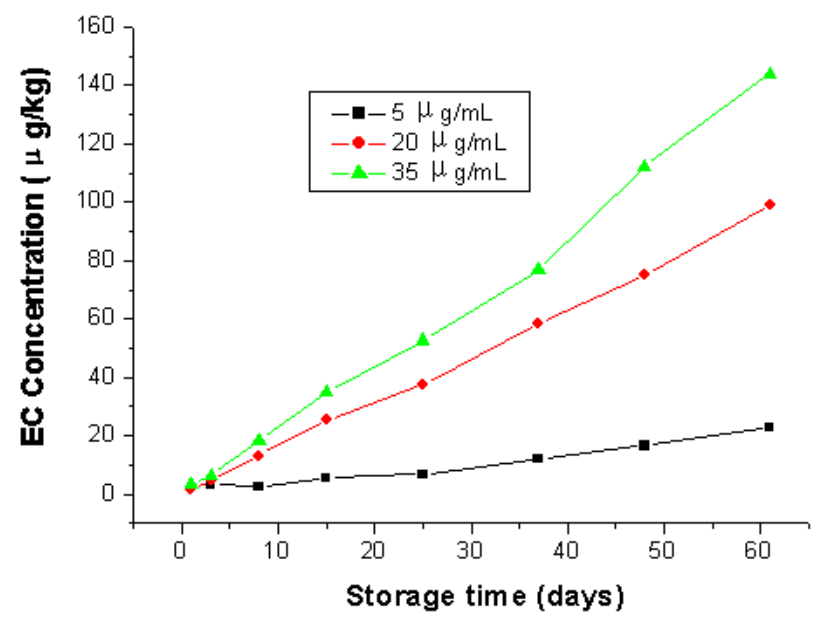

Figure 3. EC formation in solutions of urea and $15 \%$ ethanol at $37^{\circ} \mathrm{C}$

The results showed a rise tendency in EC concentration, $35 \mu \mathrm{g} / \mathrm{mL}$ urea formed more EC than 20 and $5 \mu \mathrm{g} / \mathrm{mL}$ after reacted with $15 \%$ and got $144,99.1$ and $23 \mu \mathrm{g} / \mathrm{mL}$, respectively (Figure 3). 


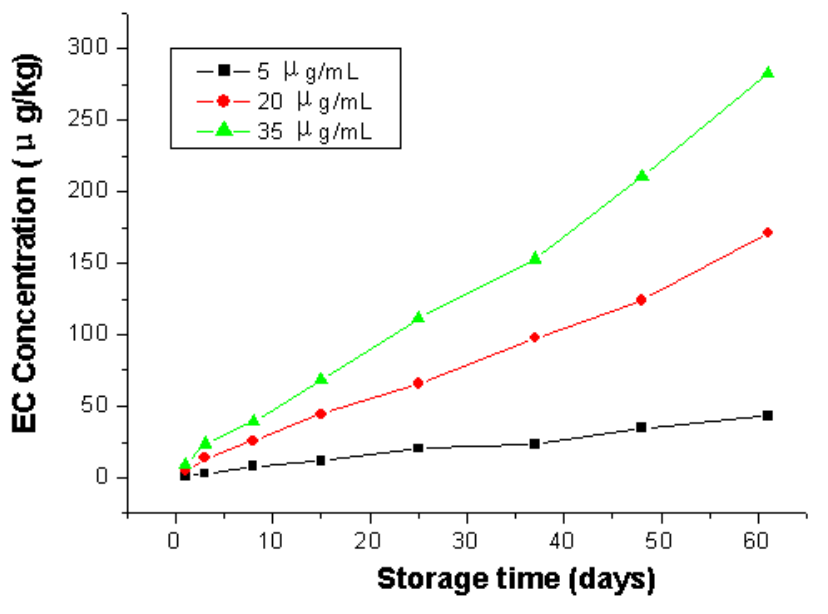

Figure 4. EC formation in urea solutions and $30 \%$ ethanol at $37^{\circ} \mathrm{C}$

As for 30\% ethanol, 35, 20 and $5 \mu \mathrm{g} / \mathrm{mL}$ urea formed 283.1, 171 and $42.8 \mu \mathrm{g} / \mathrm{mL}$ EC after 61 days, respectively (Figure 4). EC formed quickly in high concentrations of urea and ethanol compared to that of low concentrations.

To the best of our known, there were little reports about the simulated studies on EC formation in ethanol and urea mixtures. Usually the ethanol and urea in yellow rice wines were of $15 \%$ and $40 \mu \mathrm{g} / \mathrm{mL}$, respectively. Four different urea concentrations of 5, 20, 30 and $40 \mu \mathrm{g} / \mathrm{mL}$ as well as two ethanol concentrations of $15,30 \%$ were mixed at $37^{\circ} \mathrm{C}$ for over 60 days in this study. The results indicated that higher concentrations of urea and ethanol promoted EC formation. Naturally occurring EC in wines was once confirmed [21,26], which stated that EC was mainly from naturally reaction of ethanol and carbamyl chemicals, such as urea, citrulline, carbamoyl phosphate, carbanyl aspartate and etc, in which the main substrate was ethanol [23,27,28,29,30].

As for the probably genotoxic and carcinogenic effects, several ways such as utilization of urea-deficiency yeast [31], addition of acidic urease and optimization of production and storage conditions had been suggested in yellow rice wine production.

\section{Conclusions}

EC increased with the storage time in the bottled and bagged yellow rice wines during storage, EC kept an upward tendency in the first 200 days and reached 421 and $378 \mu \mathrm{g} / \mathrm{kg}$ till 600 days in the bottled and bagged wines, respectively. Urea and ethanol in high concentrations accelerated EC formation. EC increased to 591 and 189 $\mu \mathrm{g} / \mathrm{kg}$ in $40 \mathrm{mg} / \mathrm{kg}$ urea solution with $40 \%$ and $20 \%$ ethanol, respectively. After 61 days reaction of 35, 20 and $5 \mu \mathrm{g} / \mathrm{mL}$ urea with $30 \%$ and $15 \%$ ethanol, EC formed 283.1, 171 and 42.8 as well as $144,99.1$ and $23 \mu \mathrm{g} / \mathrm{mL}$, respectively. The results directly validated EC formation caused by urea and ethanol, which was also the main reason for EC increasing in yellow rice wine during shelf life.

\section{Acknowledgements}

This work is supported by the National High Technology Research and Development Program of China
(863 Program, No. 2012AA101603), the program For Zhejiang Leading Team of Science and Technology Innovation (2011R50021) and Project supported by the Open Foundation from Top Key Discipline of Mordern Agricultural Biotechnology and Biological Control of Crop Diseases in Zhejiang Provincial Colleges (2011KFJJ006).

\section{References}

[1] Beland, F.A., Benson, R.W., Mellick, P.W., Kovatch, R.M., Roberts, D.W., Fang, J.L. \& Doerge, D.R.. Effect of ethanol on the tumorigenicity of urethane (ethyl carbamate) in B6C3F1 mice. Food Chem Toxicol, 43, 1-19. 2005.

[2] Lachenmeier, D.W., Lima, M.C.P., Nóbrega, I.C.C., Pereira, J.A.P., Kerr-Corrêa, F., Kanteres, F., Rehm J. Cancer risk assessment of ethyl carbamate in alcoholic beverages from Brazil with special consideration to the spirits cachaca and tiquira. $B M C$ cancer, 10, 266. 2010.

[3] IARC. IARC monographs on the evaluation of carcinogenic risks to humans. http://monographs.iarc.fr/ENG/Monographs/vol96/index.php. 2010.

[4] Wu P. \& Chen Z.D. Determination of ethyl carbamate in alcoholic beverages by GC/MS with solid-phase extraction. J Hygiene Research, 38, 627-628. 2004.

[5] De Melo Abreu S., Alves A., Beatriz O., Herbert P. Determination of ethyl carbamate in alcoholic beverages: an interlaboratory study to compare HPLC-FLD with GC-MS methods, Anal Bioanal chem, 382, 498-503. 2005.

[6] Lachenmeier D.W., Schehl B., Kuballa T., Frank L., Senn T. Retrospective trends and current status of ethyl carbamate in German stone-fruit spirits, Food Additives Contaminants, 5, 397405. 2005.

[7] Lachenmeier D.W., Kanteres F., Kuballa T., López M.G., Rehm J. Ethyl carbamate in alcoholic beverages from Mexico (tequila, mezcal, bacanora, sotol) and Guatemala (cuxa): Market survey and risk assessment. Int J Environ Res Pub Health, 6, 349-360. 2009.

[8] Fu M.L., Liu J., Chen Q.H., Liu X.J., He G.Q. \& Chen J.C. Determination of ethyl carbamate in Chinese yellow rice wine using high-performance liquid chromatography with fluorescence detection. Int J Food Sci Technol, 45, 1297-1302. 2010.

[9] Alberts P., Stander M. A. De Villiers A. Development of a novel solid-phase extraction, LC-MS/MS method for the analysis of ethyl carbamate in alcoholic beverages: application to South African wine and spirits. Food Addit Contamin, 7, 826-839. 2011.

[10] Júnior J.C.B., Mendonca R.C.S., De Assis Teixeira Kluge Pereira J.M., Pereira J.A.M., de Fátima Ferreira Soares N. Ethylcarbamate determination by gas chromatography-mass spectrometry at different stages of production of a traditional Brazilian spirit, Food Chem, 129, 1383-1387. 2011.

[11] Liu Y.P., Dong B., Qin Z.S., Yang N.J., Lu Y., Yang L.X., Chang F.Q and Wu Y.N. Ethyl carbamate levels in wine and spirits from markets in Hebei Province, China, Food Addit Contaminants: Part $B, 1,1-5.2011$.

[12] Wu H.M., Chen L., Pan G.S., Tu C.Y., Zhou X.P., Mo L.Y. Study on the changing concentration of ethyl carbamate in yellow rice wine during production and storage by gas chromatography/mass spectrometry, Eur Food Res Technol, 235, 779-782. 2012.

[13] Wu P.G., Pan X.D., Wang L.Y., Shen X.H., Yang D.J. A survey of ethyl carbamate in fermented foods and beverages from Zhejiang, China. Food control, 23, 286-288. 2012.

[14] Wang L.J., Ke R.H., Wang B., Yin J.J., Song Q.H., Direct determination of ethyl carbamate in Chinese rice wine and grape wine by ultra performance liquid chromatography-electrospray ionization tandem mass spectrometry, Chinese Journal of Chromatography, 9, 903-907. 2012.

[15] Canas, B. J., Joe, F. L., Diachenko, G. W., and Burns, G. Determination of ethyl carbamate in alcoholic beverages and soy sauce by gas chromatography with mass selective detection: collaborative study. J Asso Official Anal Chem, 77, 1530-1536. 1994. 
[16] EFSA. Ethyl carbamate and hydrocyanic acid in food and beverages. Scientific opinion of the panel on contaminants. EFSA J, 551, 1-44. 2007.

[17] Hasnip S., Caputi A., Crews C. and Brereton P. Effects of storage time and temperature on the concentration of ethyl carbamate and its precursors in wine, Food Addit Contamin, 12, 1155-1161. 2004.

[18] Wang L.Y., Feng L., Wu P.G., Zhang J., Pan T.Q. Determination of the urea content in yellow rice wine by Spectrophotometric method, Chinese J Heal Lab Technol, 11, 3059-3061. 2010.

[19] Woo I.S., Kim I.H., Yun, U.J., Chung S.K., Rhee I.K., Choi S.W. \& Park H.D. An improved method for determination of ethyl carbamate in Korean traditional rice wine. $J$ Ind Microbiol Biotechnol, 26, 363-368. 2001.

[20] Wu J.M., Hong R.Z., Ma L.H., Xu H.Q. Determination and control of Ethyl Carbamate in the production of rice wine. Liquor Making, 3, 65-67. 2011.

[21] Ough C.S. Ethylcarbamate in fermented beverages and foods. I. Naturally occurring ethylcarbamate [J]. J Agr Food Chem, 24 (2): 323-328. 1976.

[22] Kitamoto K, Oda K, Gomi K, Takahashi K. Genetic engineering of a sake yeast producing no urea by successive disruption of arginase gene [J]. Appl Environ Microbiol, 57 (1): 301-306. 1991.

[23] Butzke C E, Bisson L F. Ethyl carbamate preventative action manual. In: U.S. Food and Drug Administration CffsaAn, editor. Washington, DC: University of California Press, 1-13. 1997.
[24] AOAC. AOAC official method 994.07: ethyl carbonate in alcoholic beverages and soy sauce. In Association of official analytical chemists, AOAC official methods of analysis (17th ed.). (pp. 14-15) Gaithersburg. MD: AOAC International. 2000.

[25] Wang Z.K., Wang Y.M., Yu QQ., Wang JG., Analysis of Ethyl Carbamate Concentration in Wine, J Food Sci (china), 9 (6):457459. 2008.

[26] Lofroth G.G.T. Diethyl pyrocarbonate: formation of urethane in treated beverages [J]. Science, 174: 1248-1250. 1971.

[27] Monteiro, F.F., Trousdale, E.K., and Bisson, L.F. Ethyl carbamate formation in wine: Use of radioactively labeled precursors to demonstrate the involvement of urea. American J Enol Viticul, 40, 1-8. 1989.

[28] Delledonne D, Rivetti F, Romano U. Developments in the production and application of dimethylcarbonate [J]. Appl Catal A: Gen, 221 (1-2): 241-251. 2001.

[29] Wang D, Yang B, Zhai X, Zhou L. Synthesis of diethyl carbonate by catalytic alcoholysis of of urea [J]. Fuel Proc Technol, 88 (8): 807-812. 2007.

[30] Stevens, D.F. \& Ough, C.S. Ethyl carbamate formation: Reaction of urea and citrulline with ethanol in wine under low to normal temperature conditions. American J Enol Viticut, 44, 309-312. 1993.

[31] Dahabieh M.S., Husnik J.I. and van Vuuren, H.J.J. Functional enhancement of Sake yeast strains to minimize the production of ethyl carbamate in Sake wine, J Appl Microbiol, 109, 963-973. 2010. 